\title{
Public participation in technological innovation: The case of the Tshulu stove development programme
}

\author{
Tafadzwa Makonese ${ }^{1^{*}}$, Christopher M. S. Bradnum ${ }^{2}$ \\ 1 Sustainable Energy Technology and Research (SeTAR) Centre, Faculty of Engineering and the Built \\ Environment, University of Johannesburg, P. Bag 524, Johannesburg 2006, South Africa. \\ 2 Department of Industrial Design, Faculty of Art, Design and Architecture, University of Johannesburg, \\ Johannesburg, South Africa
}

\begin{abstract}
The design of products for developing communities often excludes the end-users in the decision making process. The study aims to investigate public participation and engagement in the design and development of the Tshulu woodstove. Results of this research point to the need for improved communication between citizens and technical experts, as well as for narrowing the gap between the designer and the user by encouraging meaningful engagement and inclusion. Bottom-up approaches ensure sustained participation of the public, in turn increasing a sense of ownership in the product. These results have implications for energy policy and improved cookstove programmes for developing communities.
\end{abstract}

Keywords: co-design; energy efficiency; energy policy; improved cookstove

Journal of Energy in Southern Africa 28(1): 13-24

DOI: http://dx.doi.org/10.17159/2413-3051/2017/v28i1a1379

Published by the Energy Research Centre, University of Cape Town ISSN: 2413-3051 http://journals.assaf.org.za/jesa

Sponsored by the Department of Science and Technology

\footnotetext{
* Corresponding author: Tel: + 27 (0)11 559 1546;

email: taffywandi@gmail.com
} 


\section{Introduction}

It is established that over three billion people around the world depend on solid fuels, including fuelwood, coal, agricultural and animal waste, as primary sources of energy (Duflo et al., 2008). The use of these fuels in poorly designed combustion devices leads to copious emissions of products of incomplete combustion and high levels of household air pollution (Gordon et al., 2014). For example, it is estimated that annually and on a global scale, about four million people die prematurely due to smoke emissions from domestic fires (World Health Organisation, 2014; Gordon et al., 2014). There is now a clear link between smoke emissions and increased morbidity and mortality (Pope et al., 2002) especially in the global South. Continued reliance on fuelwood by a majority of rural and urban low-income areas has been linked to an increased burden on forest resources, leading to deforestation in some parts of the developing world (Masera et al., 2005; Barnes et al., 1994). The loss of forest resources leads to a loss of valuable ecosystem services (Montoya et al., 2012), a loss in habitats for maintaining biodiversity (Koh \& Wilcove, 2008) and the destruction of carbon sinks, which are useful in curbing the increasing atmospheric carbon dioxide concentrations (Wang \& Cai, 2004).

The use of energy-efficient cookstoves has been suggested as a way to contribute to the sustainable uses of forest resources (Masera et al., 2005) and there is a long history of clean fuels and efficient cookstoves being developed as solutions to energy challenges within developing communities. Early cookstove programmes (before 1980), aimed at introducing improved cookstoves (ICSs) in developing countries and focused on themes including working with and empowering women, income generation by poor artisans, and environmental conservation (Honkalaskar et al., 2013). The main goal during these programmes was to provide ICSs with high energy-efficiency during the cooking process, which was thought to bridge the gap between demand for firewood and dwindling forest resources. These early programmes erroneously assumed that, when introduced, ICSs would be adopted readily and that their introduction would lead to a self-sustaining programme (Honkalaskar et al., 2013). Barnes et al. (1994) contended that during these early stove programmes it was assumed that, since the ICSs were superior to the baseline traditional stoves, fuel consumption rates would decrease by up to $75 \%$ when using them. In fact, most of the cookstoves introduced during this era did not show huge fuel savings compared to the baseline, meaning that the programmes had failed. It became clear that chances of success for cookstove programmes are enhanced when the ICSs reduce fuel consumption significantly and when they are made by local artisans at affordable prices
(Honkalaskar et al., 2013).

From the 1980s onwards, it became evident that there was no plausible link between traditional stoves and deforestation, as people tend to use dead wood and small branches for cooking and heating (Barnes et al, 1994). The objectives of the cookstove programmes then changed to improving fuel efficiency to reduce the time taken to scavenge firewood. Researchers began to involve local people in these programmes. These programmes also largely failed, as they were not readily accepted by the rural poor. According to Honkalaskar et al. (2013), limited cookstove programmes were successful, especially in urban areas where the ICSs became economical due to fuel sales. Such success stories include the Jiko stoves in Kenya (Energy for Sustainable Development, 2000; Sanchez, 2008), the China Stove Programme (Smith et al., 1993), and the Indian national programme on improved cookstoves (Jagdish, 2004)

Only recently has the issue of indoor air pollution as a function of cookstoves come to the fore; in previous cookstove projects this was a secondary concern (Honkalaskar et al., 2013). At present there are calls to introduce energy-efficient and less polluting cookstoves and clean fuels to poor and marginalised societies. The development of such fuels and stoves was given an impetus by the advent of the Global Alliance for Clean Cookstoves. The Alliance calls for the installation of 100 million clean and efficient cookstoves and fuels by 2020 (cleancookstoves.org). Large funding agencies, led by the Clinton Foundation, the Shell Foundation, the World Bank, and the US Department of State, have created a foundation to finance, manage and lead the process of developing, evaluating, disseminating and financing ICS programmes in the developing world. The processes of designing and developing fuels and cookstoves, however, do not necessarily engage all stakeholders, including the end users (a process known as co-design or participatory design). Previous efforts adopted the top-down approach for improved cookstove programmes, with the focus on tangible technical aspects of the intervention. The majority of cookstove interventions did not take into account the context-of-use of the technologies, bringing into focus the wider social, cultural, ecological and economical context in which the target communities live. It is now widely acknowledged that the following aspects are critical for the success of every cookstove programme: (i) participation of communities; (ii) determination of user needs; (iii) study of existing practices; (iv) mimicking field results in the laboratory - 'bringing the kitchen to the lab'; (v) commercialisation and dissemination (Honkalaskar et al., 2013).

The involvement of communities in the design and development of the improved cookstove is significant to successful cookstove programmes. 
Sanders and Stappers (2008) were of the opinion that, although still unrefined, co-designing tools, techniques, and processes for meaningful engagement, are growing rapidly. Hussain et al. (2012) contended that, despite the growing literature on participatory design in developing countries, there is still a need for more in-depth analyses and case studies exploring both the challenges and opportunities for conducting participatory design projects for marginalised people. Van Veggel (2005) highlighted the need for designers to include ethnographic research in the design process, including studying routines, the tools required to perform daily tasks, and the physical and social environment. This is done to translate understanding of the users' needs and behaviours into the final design product. According to Sanders and Stappers (2008), in co-design, the user becomes an expert (as a function of their experience) and plays a critical role in the idea and concept development. Central to the co-design process is the proposition that people who are affected by a product should have an opportunity to influence the outcome, a way of democratising the decision-making process and outcome (Hussain et al., 2012). The role of the designer, by necessity, then changes from design expert to facilitator of the design process (Manzini \& Rizzo, 2011).

In most African countries, including South Africa, a gap in knowledge exists in the areas of contextually relevant participatory design methodologies including co-design and co-creation processes. There is a need to understand people's needs to design and develop an ICS that can be socially and economically acceptable to the target communities. As such, there is an opportunity to contribute to the methods and approaches required to train non-designers to co-design and to co-create. Honkalaskar et al. (2013) argued that dissemina-

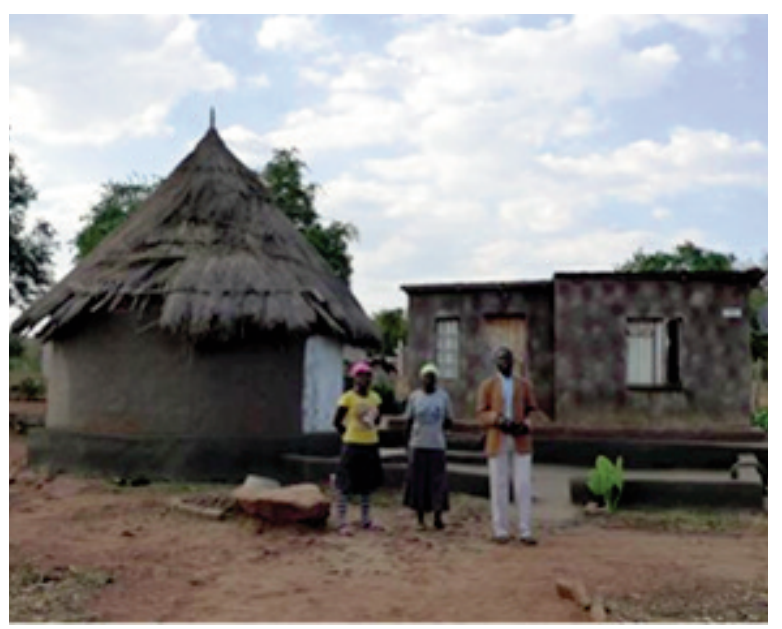

Figure 1: Typical household layout in HaMakuya village showing a detached thatched kitchen and an electrified brick house. (All photographs in this paper by Chris Bradnum) tion programmes are most effective when they allow for interaction and feedback between stove designers, producers, and users.

In light of the above, this research aims to analyse public participation in the design and development of an improved wood-burning cookstoves, which we have termed the Tshulu stove. The study interrogates the inclusion of end users as co-designers, in the design and development process. Steps were taken towards addressing the limitation in the design discourse, by examining principles used to devise a wood burning stove. This was done through direct engagement with people in the HaMakuya rural district, Vhembe Region, Limpopo Province, in South Africa. The stove development followed a bottom-up or user-centred design process, combined with co-design workshops.

\subsection{Case study area}

This study was carried out in HaMakuya rural district, Vhembe Region, Limpopo province, in South Africa. Limpopo has a population of nearly 5.5 million, and is the country's fifth-largest province. Of that population, $50 \%$ are unemployed (Statistics South Africa, 2011). This is well above the South African average of $25 \%$, revealing Limpopo as one of the poorest regions in the country. The HaMakuya District includes HaMakuya village, Tshikalini, Mutshikalini, Dotha, Mbuyuni, Musunda and Guyuni, among others. The project was conducted through the Tshulu Trust, a non-profit organisation based in the area, which facilitates research projects in this rural region. The population in this district is $\sim 5000$ people. HaMakuya is located $600 \mathrm{~km}$ north-east of Johannesburg and the area forms part of the foothills of the Soutpansberg range. The district is located less than $30 \mathrm{~km}$ from the Zimbabwe border, and only $10 \mathrm{~km}$ from the Kruger National Park (Statistics South Africa, 2011), but the villages are remote and can only be accessed via a poorly maintained gravel road. Each household is situated on a small piece of land allocated by the local authorities (see Figure 1). On these plots, households often have a small vegetable garden, and farm animals including chickens and goats. The region is semi-arid and prone to periodic droughts, with summer temperatures reaching $40{ }^{\circ} \mathrm{C}$, dropping to a moderate $12{ }^{\circ} \mathrm{C}$ in winter. Rainfall occurs between October and March, reaching a peak during January and February, and can be as low as $340 \mathrm{~mm}$ per year (Berger et al., 2003). The vegetation includes sparse scrub, and small trees interspersed with grass.

The majority of households in HaMakuya depend on fuelwood as a primary energy source to meet their basic heating and cooking needs. The fuel is used in an open three-legged grate stove. Cooking is generally done in closed cooking huts, or outdoors in an area allocated for cooking. 
Households use potjie pots, which are three-legged cast-iron pots with a lid and wire hanging handle. The size 3 ( 8-litre) pot is common. Other types include Hart $^{\mathrm{TM}}$ aluminium pots, with the 5-litre pot being common. Households usually have a couple of larger pots for religious activities or family gathering and festivities. Firewood is collected from the areas around the villages and collection of firewood and management of trees is strictly controlled by the area chief, the village headman, and councillors.

\section{Methods and experiments}

The study employed a bottom-up approach to emphasise the need for including local context in the design and development of ICSs. Bottom-up approaches in co-design have been shown to provide socially and technologically appropriate solutions; thereby increasing the acceptance and widespread use of the technologies (Honkalaskar et al., 2013). Public participation (decision-making and planning) was encouraged and sought at every stage of the process to develop an efficient woodburning cookstove. As such, the project followed a number of research and design stages. Emphasis was on the contextual uses of fuel/stove combinations in the target area. The first stage was an initial energy survey in which the researcher engaged with households on the current energy problems they were facing, including the technology and energy used for cooking. Co-design workshops were set up with field-testing informants to allow the end users to engage directly in the design and development of the Tshulu stove. The co-design process followed typical design processes, which included:

- problem identification and understanding of local context;

- a precedent study of existing and in-use cookstoves in the target community, through an analysis of existing stove technologies or other stove technologies being rolled-out through international programmes;

- reference material analysis - these are inspirational materials that the participants can use to create and design a new stove;

- design and local manufacturing of a suite of prototype cookstoves - using the local skills base;

- field experimentation of the designed cookstove prototypes; and

- performance improvement of existing prototypes.

\subsection{Questionnaire administration}

The research was based on quantitative research methods, involving the use of direct observations, unstructured interviews, focus groups and co-design workshops. The study sample was determined using purposive sampling techniques. The main advantage of purposive sampling is that the researcher can research a target sample quickly and can draw on a wide range of qualitative research designs. A household energy survey was developed to determine the baseline household energy-use scenario data for the area. This information was important for identifying problems related to cooking-fuel uses, and understanding the role which energy plays in the lives of rural people. Although the intention was to interview 100 households, only 58 of the surveys were completed. For this phase of the project, four experienced interpreters from HaMakuya district were appointed by the Tshulu Trust. The household energy use survey focussed on energy access, use of the various forms of energy, and household cooking practices. Data analysis was completed using a statistical software package for the analyses of variance by the Statkon Department at the University of Johannesburg. Informed consent was obtained from the respondents prior to the investigations.

\subsection{Public participation}

The people in the HaMakuya village contributed to the public participation discourse in the following ways: (i) identifying problems associated with using cooking fuels inefficiently; (ii) identifying existing cooking practices; (iii) in discussions pertaining to design concepts of the prototype stoves; (iv) local artisans were employed to make the prototypes using materials provided to them; (v) participating in the field experiments; (vi) and participating in the modifications of the prototypes based on the knowledge gained in the field surveys. Participation was generally achieved through face-to-face interactions in co-design workshops. The participants consented to take part in the study and the publication of any images where deemed necessary. The participants were also advised prior to the study that they had the option to withdraw their participation at any time. The researchers and stove promoters participated at each phase of the process. Co-design workshops are briefly discussed in section 2.2.1.

\subsubsection{Co-design workshops}

Two design workshops were conducted with 33 intended users of the Tshulu stove, selected based on their understanding of energy dynamics in the area; the four stove designers; and six promoters (including the interpreters) over four days, with two days reserved for each workshop. Using in-depth ethnographic studies, we explored the participants' perspectives on the design features of wood-burning stove technologies to facilitate the co-production of new and novel ICS technologies. Discussions during the co-design workshops were audio-recorded and transcribed at a later stage. The workshops were intended as an experimental method to investigate how to include end-users as decision-makers in the function, ergonomics and aesthetics of the wood burning stoves. This was 
premised around the work of Hussain et al. (2012), where it was found that everyone has the potential to design if given the right tools and the relevant knowledge. Participants were first trained in the stages of the design process and then asked to go through the design process with minimal assistance. Two interpreters from the Tshulu Trust were included throughout the process to give feedback, and to ensure the objectives were clearly articulated and that the responses of the participants were clearly relayed.

The first workshop involved telling stories to participants, albeit fictional, about the problems and dangers of using inefficient and polluting cooking and space-heating devices. The workshop facilitators presented these stories before they opened them up to the workshop group for discussions. After comprehensive discussions, participants were introduced to the co-design process, which they could use in providing solutions to some of the identified issues. The second day of the initial workshop focused on the development of the devices. A detailed description of the process is provided in Section 2.2.2. The final co-design workshop was carried out after the stoves had been developed, deployed and used in the target community for a period of six months. The purpose of this workshop was to gather information on the suitability and acceptability of the Tshulu wood-stove in the HaMakuya District. The participants were asked to critique the stove based on their hands-on experiences and provide possible feedback and solutions. The intention was to include the information to improve the stove in terms of appearance and cooking performance.

\subsubsection{Stove development and modifications}

Steps were taken towards addressing the limitation in design discourse, by examining principles used to devise a wood-burning stove. This was done through direct engagement and consultation with people in the HaMakuya rural district. The stove development followed a user-centred design process, combined with co-design workshops (see Section 2.2). Participants were asked to use materials supplied by the researcher - clay and wire (with tools), and pencils with paper - to design an ideal stove for their own use. The participants were directed to use whichever type of material they were most comfortable with for this design exercise. Participants who preferred to make models were asked to make these models as one-fifth scale models. A one-fifth scale two-dimensional articulating anthropometric model was given to those participants who preferred to make physical models. A one-fifth scale model is used to avoid the model becoming too big to be practical, it remains possible to show enough detail (air-holes, fuel-hopper, stove handles). The participants were given three hours to complete this task. At the end of the stove design phase, participants were required to present their designs to the group and group members were asked to give feedback on these designs. Three prototype stoves were manufactured for initial fieldtesting, based on the information received from the co-design workshops. The stove technology used for the inner working of the Tshulu stove was based on the 'rocket stove' design developed by Aprovecho, in the USA (www.aprovecho.org). The first concept, referred to here as RS1, was developed based solely on the Aprovecho design (Bryden et al., 2005) (Figure 2) without further alterations.

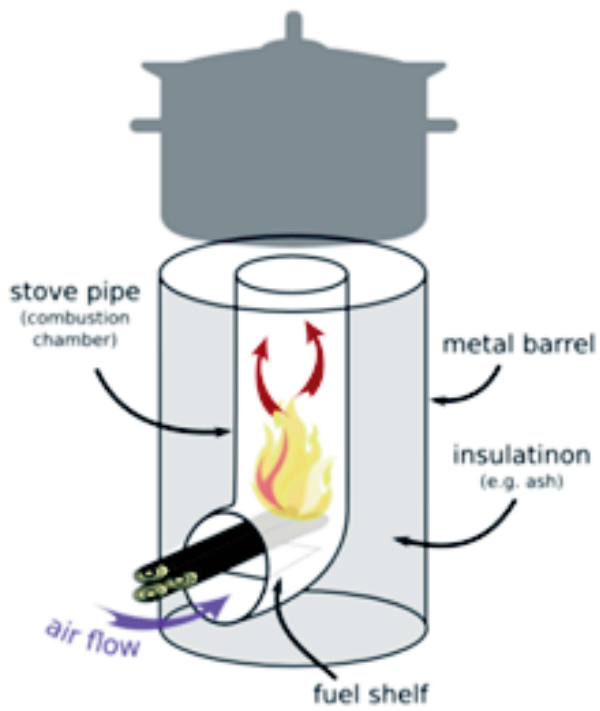

\section{Figure 2: A schematic of the rocket stove principle (https://en.wikipedia.org/ wiki/Rocket_stove).}

The other two designs, referred herein as Tshulu1 and Tshulu2, were based on the same rocket elbow principle but had further design alterations and improvements, which included a removable ashtray and a primary air inlet below the combustion chamber. The Tshulu1 had a smaller wood inlet (D in Figure 3 ) and proportionally smaller vertical flue diameter; while the Tshulu2 had a larger wood inlet chamber ( $\mathrm{A}$ in Figure 3 ) and increased flue height and flue diameter.

\subsection{Field-testing procedure}

The Tshulu Trust prearranged village meeting times at the five villages identified. The research manager of the Tshulu Trust, through consultation with the district chief, visited villages in the district to request permission to conduct this research project. Each village was visited before $10 \mathrm{am}$ to ensure the research did not interfere with the day's work. Once an agreement had been reached, the headmen and councillors of each village selected participants for 


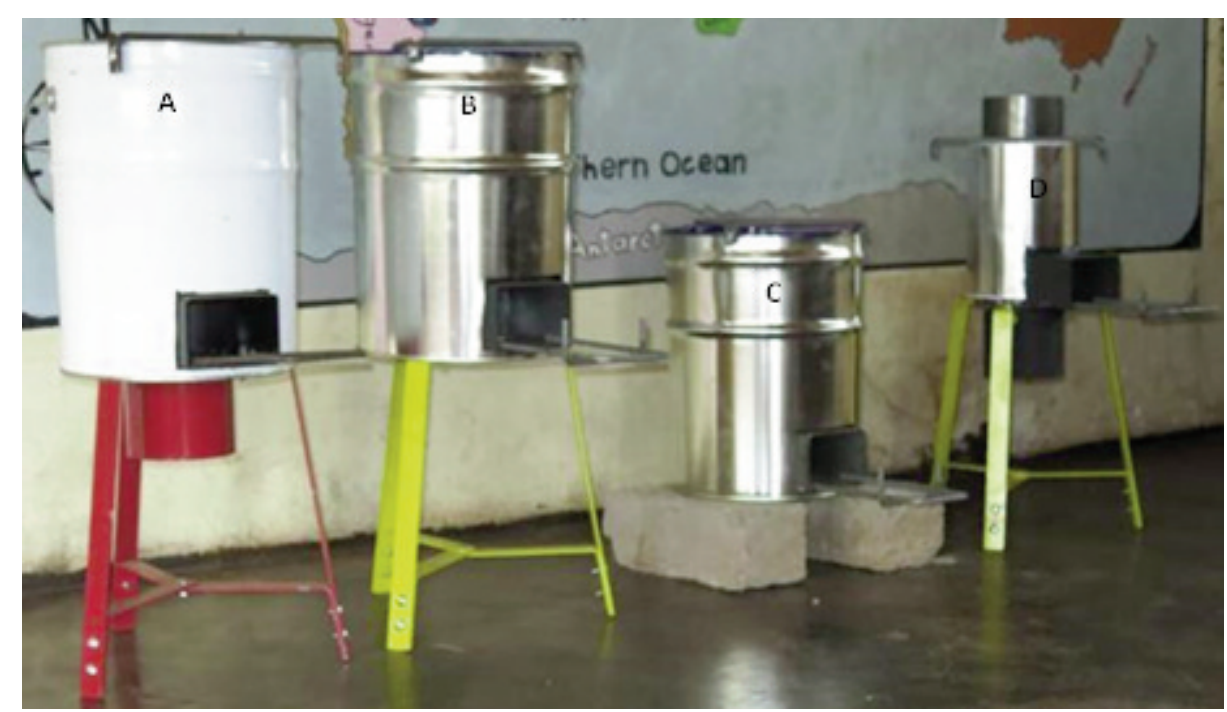

Figure 3: The Tshulu stoves: (A) Tshulu2 with ash remover; (B and C) RS1 and RS2 based on the Aprovecho designs; (D) the smaller design Tshulu1.

the project before the stoves were delivered. In some villages, this was completed on a democratic basis, where the headmen and councillors nominated households that would benefit most from the use of the technology. In other villages it was done on a political basis where the headmen selected favoured households. Thirty prototype stoves, including ten of each variant (Tshulu1, Tshulu2, and RS1), were manufactured and field-tested for six months over the summer months of October 2014 to April 2015, across the five villages. The RS2 prototype stove was not used in the survey as the householders preferred cooking while standing. For every household using the Tshulu stove, a household using a typical traditional stove (open fire) was selected for comparison. Thus, 60 households were included in the field-testing process, which compared typical wood-usage profiles over the same period of households using the stoves and those cooking on open fires. The comparison group were informed that if they completed the six-month data collection they would each be supplied with a stove. At each village, a demonstration on how to use the stove was conducted and the use of logbooks and data capturing system was explained. Each household was given a log-book, pen and hand-held fishing scale to record the mass of wood bundles. The participants were asked to record the date of wood collection, the mass of the wood collected, the number of meals cooked per day, the number of members of the household being catered for and any issues encountered when using the stoves.

\subsection{Final co-design workshop}

The final design co-workshop included discussing the experimental stove field surveys with the participants. The participants used information from the field survey to critique the stoves and to suggest improvements to be include in the final product.
About 20 local stakeholder participants took part in this exercise. The local stakeholders, researchers and designers from the University of Johannesburg, and stove promoters from the Tshulu Trust participated in this exercise.

\section{Results and discussions \\ 3.1 Household energy survey - understanding the present context}

Surveys were carried out in the HaMakuya district to understand the present context and identify any potential gaps or problems related to household cooking and heating fuels. The survey confirmed that the majority of people in HaMakuya are unemployed; they survive off government grants or informal employment, and subsistence farming. About $66 \%$ of households interviewed survive on under ZAR 1500 (USD 100) per month, while 80\% of respondents indicated that they either were unemployed, on pension, or were occasionally employed informally. Although $93.1 \%$ of households have electricity, this is mainly used for lighting (91.2\%), with $7.0 \%$ using candles, while a further $1.8 \%$ use kerosene lamps. About $92.5 \%$ of households with electricity have prepaid electricity meters, spending an average ZAR 50 (USD 3.3) per month. Candles and kerosene lamps are used interchangeably, although the use of candles for lighting is common in this area. Respondents pointed that kerosene lamps are inefficient, produce smoke that irritates the eyes, and make the room smell of kerosene fumes. This result is contrary to findings by Masekoameng et al. (2005) who found that in the Giyani area in Limpopo, kerosene lamps were popular for lighting compared to candles. The differences in these areas could be attributed to different socio-economic profiles of the two areas.

The continued use of certain fuels in most lowincome settlements is influenced by the availability 
and cost of the energy carrier. If the fuel is costly and not easily accessible, households tend to use cheaper alternatives. The majority of respondents (79\%) use wood as the primary energy source for cooking, while $21.1 \%$ use electricity for cooking. Mopane trees (Colophospermum mopane) are generally considered high-energy carriers in the area and are the predominant choice for harvesting for energy use. Based on the questionnaire surveys, households use $12 \mathrm{~kg}$ of fuelwood, on average, to meet their daily energy needs. About $91.4 \%$ of the households surveyed use fuelwood for space-heating, while $69.1 \%$ use it for water-heating. Some households supplement fuelwood with kerosene when wood is not available or is too wet to combust. Of the interviewed households, $89.7 \%$ collect their own firewood, $5.2 \%$ gather the fuel and pay to have the fuel delivered to their households, while $5.1 \%$ purchase and have the firewood collected and delivered to their doorstep. The firewood is collected from forest resources surrounding the villages.

Women and girls play a significant role in collecting the fuel - results from the survey indicate that $56.9 \%$ of firewood is collected by women. Unless the household has a cart, or a pickup truck ('bakkie') the fuel is generally carried on the head. The involvement of men in household chores such as fetching or cutting wood is minimal in this area. However, similar to findings by Masekoameng et al. (2005), it is men who make decisions on what energy sources and energy technologies a household should use. Firewood is generally collected twice a week with each trip taking three hours, on average. The average distance to collect firewood is five kilometres in any direction. Thus, collecting wood in HaMakuya is both time-consuming and energyintensive. In a similar study conducted in Giyani, Limpopo, Masekoameng et al. (2005) reported that women spent on average five to six hours per day collecting fuelwood. In Mahlabatini district, KwaZulu Natal, the average time spent collecting fuelwood was about nine hours per household per week in the highlands and seven hours per household per week in the valley (Gander, 1992). Of the interviewed households, $72.6 \%$ cook in a purposebuilt kitchen, $22.6 \%$ cook outdoors, while $4.8 \%$ cook in the main house. A three-legged stove is used by $58 \%$ percent of households; $8.7 \%$ use a three-stone fire, $31.9 \%$ have built-in fireplaces, and $1.4 \%$ use rocket stoves. Typically, households cook at lunch and supper, and seldom in the morning. The meals include thick maize meal porridge, vegetables, and occasionally a meat relish. Lunch is the most important meal of the day. Meals take an average of one hour to cook.

\section{Problem identification}

According to Aref and Redzuan (2009) and Honkalaskar et al. (2013), the effectiveness of any technological innovation and dissemination process increases when the intervention addresses pertinent questions or problems that are of high priority in the target area. Hence, it is imperative to identify key concerns in the target communities where ICSs could play a significant role. The problem identification stage included discussion with participants about the broader issues of deforestation, conservation of limited resources, the change from open-fire cooking to wood-stove cooking, and the issues related to open-fire cooking. This took some time as each sentence was translated into TshiVenda language by the Tshulu Trust interpreters. At times the interpreters disagreed with each other's use of the language, which made the thread and flow of the discussion difficult to follow.

The problems reported in the survey when cooking with open wood fires included burns $(20 \%)$, eye irritation $(19.6 \%)$, breathing problems (14.3\%), and poor visibility when cooking $(12.2 \%)$. House fires $(9.4 \%)$, on the other hand, are generally caused by kerosene stoves and candles. The respondents indicated that they needed better and improved cooking technologies that would address these concerns. Features looked for in the improved stoves in order of preference were indicated as (i) durability; (ii) low smoke levels; (iii) fuel efficiency; (iv) standing working height; (v) two or more plates on the cooker; and (vi) portability and safety. Other important features noted were the need for a chimney, visual appeal, and the potential for baking, storing and drying wood. A device that addresses all of the above would be expensive for the villages, given their limited income levels, but respondents indicated that the cost of the device was a least priority.

\subsection{Initial co-design workshop}

A series of aspects were analysed in detail during the first co-design workshop. These factors included analysis of available technologies, analysis of reference materials to be used for the design of cookstoves, and stove development.

\subsubsection{Analysis of available cooking technologies}

During this phase, we analysed the cooking technologies available in the village. Two pages with an open-fire three-legged stove represented on each page were presented to the participants. The participants were then asked to evaluate the merits and demerits of open fires. The responses were captured on the drawing pages. The responses were categorised as 'good' and 'not good' on each of the drawings (see Figure 4).

The participants raised a number of important points regarding the size of pots and the size of the wood that could be used on the standard threelegged cookstove when discussing open-fire cooking. They recognised that open fires were an ineffi- 
cient in wood consumption. Again, there was a safety concern and an implication for health that they had experienced over time.

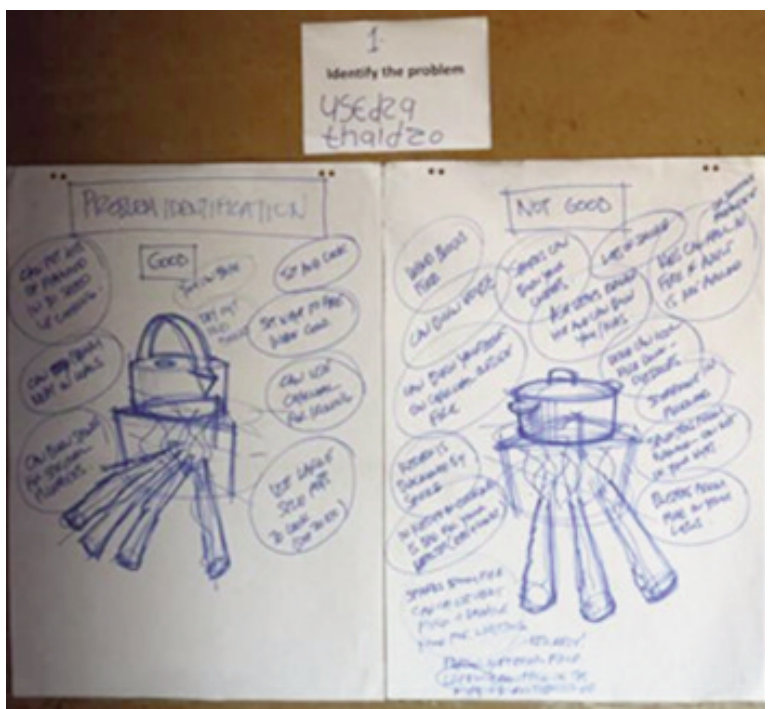

Figure 4: Drawings to discuss the merits and demerits of current cooking technologies.

\subsubsection{Reference material analysis}

For the second day of the co-design workshops, the participants were asked to bring in inspirational materials that they could use in the design of a new stove. It was suggested that participants focus their attention on the materials and details they would like to see in their ideal cookstove. They were also asked to look at the colour and other products that may contribute to the discussion. A number of magazines were supplied as additional reference, and participants were directed to these to cut out inspirational reference materials if they did not already have access to these materials at home. They were also encouraged to bring in physical items if they considered these to be effective inspirational materials. Some participants asked for clay to create their own reference materials, while others asked for paper and drawing materials for the same purpose. When the reference materials were presented for

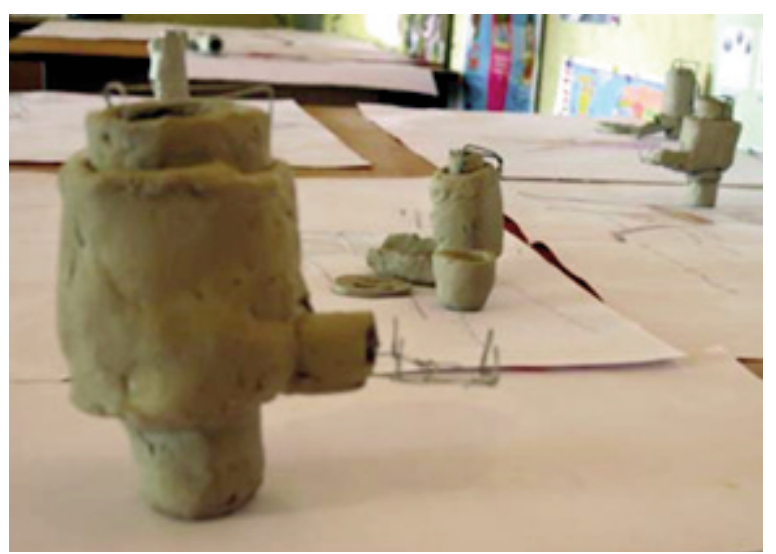

Figure 5: Clay models of the proposed stove made by participants. discussion, they included some well-crafted aspirational products, replicas of standard household products with elaborate decoration (see Figure 5), sketches of inspirational artefacts, and some images cut from magazines.

In future projects, a pre-screening process for participants might be useful. Some of the participants in these workshops showed real skill in clay modelling and some in drawing. During the prescreening phase, critical thinking and the design capability of participants should be identified and people showing acumen in these areas retained for more complex design process training. This could include materials and manufacturing training, thereby allowing more time for the individuals to develop the projects further. A further consideration would be to extend the design phase for participants to construct complete prototypes for evaluation. This would entail processes such as concept development, refinement, modelling, and design and development of the product.

\subsubsection{Stove development}

The technology selected for this stove carefully considered the need to improve the health of the end user, the cooking practices of the region, and protecting the environment by reducing fuel consumption rates. This phase of the design process included 33 participants (three quarters of them female), the stove researchers and designers from the University of Johannesburg, and the stove promoters, Tshulu Trust. It should be noted that the local stakeholders were highly involved and consulted at every phase of the process.

The design embodiment was arrived at because of a purely pragmatic decision-making process. This included factoring in cost, standard components, and the need to fit three variants of the stove into the same stove housing. The outer shell or stove body was manufactured using a 20 litre metal paint tin (obtained free of charge or at reduced cost from some paint-making industries) as it comes with a custom made handle and has enough structural integrity to hold safely a large pot on a pot stand. The inner five-litre tin fitted around the combustion chamber creates a pocket of insulating air to reduce heat loss, thereby increasing the overall efficiency of the stove. The legs were constructed from inexpensive flat bar metal that support the entire stove. The wood inlet, combustion chamber and flue diameter were designed based on the proportional dimensions proposed in the Aprovecho manual (Figure 6). However, these dimensions were adjusted to suit the standard metal tube sizes available in South Africa. The size of the combustion chamber was calculated based on tube diameters and the subsequent internal volumetric area. From the survey findings, standing-height cooking was selected as a baseline. During the stove design phase, pho- 
tographs were taken of one of the interpreters working at the stove at sitting height and at standing height. These were then printed out and the participants were asked to blind vote on which height was most preferable. The blind vote revealed that $50 \%$ of the participants preferred cooking while standing and that $50 \%$ preferred cooking while seated.

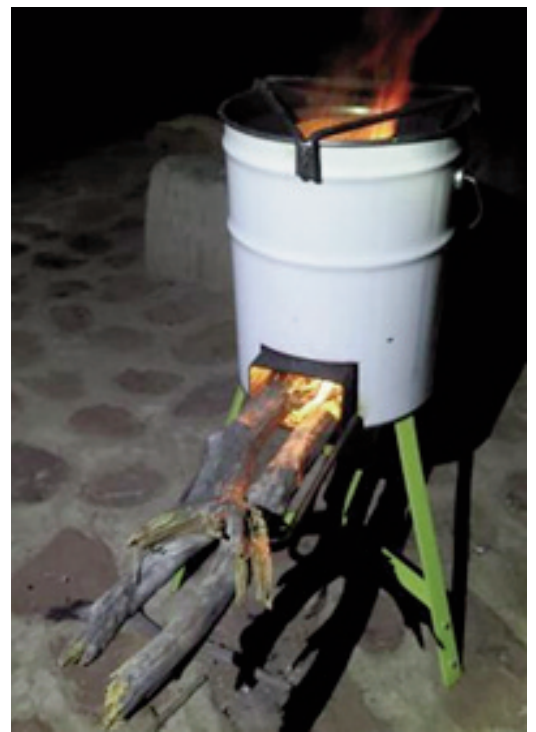

Figure 6: Tshulu stove with improved design principle.

\subsubsection{Local artisans}

A portion of the investigation of the area was also to ascertain the potential of local artisans to be involved in the manufacturing process to make solutions locally. It was found that there are two skilled craftsmen in the HaMakuya village from Mozambique, who live in the area and manufacture the 'Chichakuluma' kettle (Figure 7), which is found in the majority of households in HaMakuya. The sheet metal used for making the kettles is purchased from Johannesburg and delivered to the village once a month. All components of the kettle are made using hand tools at the artisan's outdoor manufacturing site.

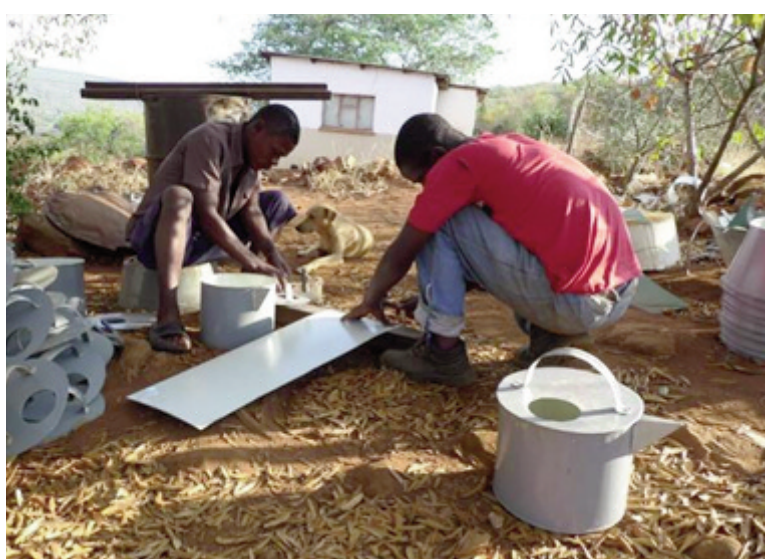

Figure 7: Local artisans manufacturing the 'Chichakuluma' kettle.
The artisans indicated that they would be interested in manufacturing the Tshulu stove and providing a service to the villagers. According to Honkalaskar et al. (2013), such a bottom-up approach is essential and a prerequisite for the development of local human skills and can be useful in establishing a sustainable local socio-economic structure. The success of the dissemination of improved cookstove technologies is dependent on a number of interlinked factors, which vary with context (Ramirez et al, 2012). Jagdish (2004) as cited in Honkalaskar et al. (2013) contends that local enterprises that disseminate stoves, even after having gone through rigorous training, often get poor benefits, resulting in there being little motivation to start and run the business. Thus, in the present context, the manufacture and dissemination of the Tshulu stove is sought through existing business structure of the local craftsmen. The technology can also be disseminated through the involvement of the Tshulu Trust.

\subsection{Field stove experimentation results}

The men were required to make the decision regarding the distribution or redistribution of the stoves even though their likely users would be the women. Patriarchy and traditional societal norms and practices increase the complexity that needs to be managed when introducing interventions in such societies. During the field trial period, it was found that the design based on the original Aprovecho rocket stove (RS1) was difficult to light and the flame could not be sustained for cooking. About $40 \%$ of the participating households simply stopped using the RS1 stove, resorting to using the threelegged stove. The reason for failure of the stove to maintain a flame during cooking is that the air inlet below the grid became clogged with ash within a half an hour of lighting, effectively starving the burn area of oxygen. It is also unsafe to clear the ash from the combustion chamber when the stove is still burning.

The survey showed that $100 \%$ of respondents indicated that they preferred standing when cooking, which contradicted the co-design workshop findings (where half the vote went the other way see Section 3.2.3). In most Southern African patriarchal societies, women are expected to cook while sitting or kneeling. Standing while cooking, and especially towering above males seated in the kitchen, is generally considered taboo and disrespectful.

Ninety percent of the respondents indicated that they found they had less breathing difficulty, better visibility and less eye irritation when cooking on a Tshulu stove. This implied that the stove was efficient in reducing noxious emissions, which are caused by the incomplete combustion conditions common in traditional open fires. However, perfor- 
mance evaluation of the stoves under a test rig will be required to substantiate this claim quantitatively. All respondents interviewed indicated that they liked Tshulu prototype stoves and that they would be happy to pay 'something towards purchasing the devices. About $50 \%$ indicated that they would be willing to pay ZAR 300-400 (USD 20-27) for the stove; the other $50 \%$ would pay half that amount. A stove selling for more than ZAR 500 was considered too expensive (the majority of the households earn less than ZAR 2000 per month). However, the respondents indicated that cost was not a priority, provided the device addressed all their energy concerns. About $75 \%$ of the respondents were concerned that the stove only accommodated certain pot sizes. An obvious problem that was overlooked when making the stove prototypes is that households require two dishes of food to be cooked concurrently. It was found that nearly all of the households supplied with stoves were using the stove for one component of the meal and the open fire and three-legged metal stove for the second component, thereby invalidating the logbooks and data related to wood usage.

Not all the logbooks were completed. Twentyfive of the stove field trial group returned the wooduse logbooks. The average wood use for these households was $4 \mathrm{~kg}$ per day, with some recording as little as $2 \mathrm{~kg}$ per day. Of the comparison households set up at the beginning of the research, only 13 completed the process, with one participant wittingly falsifying data by repeating the daily wood weight measurement throughout the trial. The average household wood use for the comparison group that did complete the logbooks averaged around $7 \mathrm{~kg}$ per day, which was lower than the $12 \mathrm{~kg}$ per day originally found in the household energy survey. This discrepancy could be attributed to the use of mass measuring instruments during field tests versus fuelwood mass assumptions in the questionnaire.

\subsection{Final co-design feedback}

During the final co-design workshop, the participants were asked to review the stoves based on their expectations and experiences, and to suggest how to improve the existing design into an acceptable model. Initially, the participants were reluctant to critique the Tshulu stoves, as it is generally considered disrespectful in the TshiVenda culture to speak ill of someone's innovation in their presence. Nonetheless, after being encouraged through selfcriticisms from the designers and stove promoters, the participants raised the following pertinent suggestions:

- the handle position should be changed to allow for the stove to be moved in and outdoors during the cooking process;

- there should be an increase in material thickness in the body area to increase stove durability;

- a double-plate stove is needed;

- there should be a larger wood inlet to cater for larger pieces of wood;

- the stability of the stove should be improved for when large pieces of wood are loaded into the combustion chamber.

Some of these improvements would increase the costs of a commercial stove and some might have safety implications. However, it is worth noting that participants focused on practical aspects and were critical of weaknesses or perceived weaknesses in materials and the manufacturing process. Little attention was given to the aesthetics of the stove.

\subsection{Lessons learnt and implications of results}

The participants raised concerns about the need to increase awareness of ICSs and the dangers of using traditional stoves and fuels. The users were motivated through the workshops and engagements to critically explore how the technology could support them to meet their basic cooking and heating needs. They felt, however, restricted by the lack of information about different fuel/stove technologies, and guidance. On the same note, the stove designers and promoters identified the need to increase public awareness about improved woodburning stoves. Participants, on the other hand, highlighted that there is great value in learning about technology and innovation through direct interaction and participation in groups or social gatherings. They indicated the need for informal social support structures through local networks, to introduce improved cookstoves such as the Tshulu stove into their communities.

The promoters emphasised that staff at the Tshulu Trust should continue to support the users in the HaMakuya district with technology designed to meet their immediate energy requirements. This would also ensure that the Trust forms a sense of familiarity and presence in the area. Consequently, the Trust would build a positive relationship with the product users. The promoters of the technology recognised the importance of maintaining a positive relationship with the end-users, for the effective implication and use of the cooking devices and potential products that they might want to introduce into the community. The participants also indicated that technical services for the maintenance of the devices needed to be put in place, through the empowerment of the local youths. Hence the design, development, dissemination and maintenance of the devices should focus on social cohesion to support the end users and should not be made 'independent' of the target groups. This would have the added advantage of allowing the communities to own the product and continue to 
use it over an extended period of time.

Findings from this study have important implications for rural energy policy and ICS programmes for developing communities. Concerning ICS programmes, the research points to the need for improved communication between target communities, technical experts, and decision makers. Findings presented herein narrow the gap between the designer and the user by encouraging meaningful engagement and inclusion. Bottom-up approaches to energy issues would ensure a sustained participation of the public, which in turn increases a sense of ownership in the product. However, the issue of when and how to include end-users as co-designers creates a number of problems for designers. In designing energy-efficient products, individuals who can contribute meaningfully are often difficult to identify. In the context of a rural region with about 5000 inhabitants, the potential is even smaller. However, in these areas, there may be a mix of good informal designers, illustrators or communicators, and some pragmatic and critical thinkers. Finding ways to harness the insights of communities pertaining to energy-efficiency projects would be crucial for co-design to become meaningful. In future technological innovations in the country, focus should be placed on those aspects that can be contributed by the target communities; how their unique experiences can influence the function, ergonomics, and the aesthetics of energy-efficient products.

\section{Conclusions}

This paper presented the results of a novel study of domestic energy uses and public participatory design in a technological innovation project involving the development of the Tshulu wood stove. Participants identified the need for continued engagements with the stove developers and that any intended technology targeted at the communities should address their immediate energy needs. In addition, the stove developers and promoters should be aligned with the target community's social networks and support groups to provide information pertaining to improved biomass cookstoves and to track the communities' needs over time. Future work should focus more on the role of similar engagements of ICS technologies at large scale to identify the techno-organisational changes required for introducing and supporting ICSs. Although the Tshulu stove has not been commercialised yet, input received from the participants in HaMakuya has added significantly to stove design capacity and to recognising the value of public participation in technological innovation. The final prototype of the Tshulu stove is still under development and it is envisaged that the final product will be tested in the field, in the same district, before being commercialised through local business structures.

\section{Acknowledgements}

The authors would like to thank the following people and organisations for their contribution to this research project: The Department of Industrial Design, University of Johannesburg - Martin Bolton, Kyle Brand, Vincent Molapo and Michelle Molapo; the Faculty of Art, Design and Architecture, University of Johannesburg - Prof Kim Berman; SeTAR Centre, University of Johannesburg Crispin Pemberton-Pigott; the Energy Centre, Cape Peninsula University of Technology - Prof Harold Annegarn; University of Johannesburg Manufacturing Research Centre - Dr Tiaan Oosthuizen; the Tshulu Trust and Research Centre - Dr Lara Allen, Oisin O Connor, Rueben, Fanie, and Marylynth; and the University of Johannesburg STATKON - Dr Jacklyn de Klerk and Dr Richard Devey. The authors would also like to thank all participants in the HaMakuya District.

\section{References}

Alem, Y., Beyene, A.D., Kohlin, G. and Mekonnen, A. 2014. Determinants of household fuel choice in urban Ethiopia. The environment for development Discussion Paper DRB 13-12 . Addis Ababa, Ethiopia.

Aref, F., Redzuan, M. 2009. Assessing the level of community participation as a component of community capacity building for tourism development. European Journal of Social Science 8: 68-75.

Barnes, D. F., Openshaw, K., Smith, K.R., van der Plas, R. 1994. What makes people cook with improved biomass stoves? A comparative international review of stove programs. World Bank Technical Paper No. 242, Washington, DC.

Berger, K., Crafford, J. E., Gaigher, I., Gaigher, M. J., Hahan, N., and Macdonald, I. 2003. A first synthesis of the environmental, biological \& cultural assets of the Soutpansberg. Louis Trichardt, South Africa: Leach Pinters \& Signs CC.

Bryden, M., Still, D., Scott, P., Hoffa, O., Ogle, D. Bailis, R., and Goyer, K. 2005. Design principles for wood burning cookstoves. Available online at: http://www.aprovecho.org. Viewed June 2013.

Duflo, E., Greenstone, M. and Hanna, R. 2008. Indoor air pollution, health and economic well-being. Surveys and Perspectives Integrating Environment and Society 1: 1-9.

Energy for Sustainable Development. 2000. Poverty reduction aspects of successful improved household stoves programmes, Final summary report, Report No. DFID KaR R7368, Energy for Sustainable Development Limited, UK.

Gander, M. 1992. Domestic energy used by farmworkers living on commercial farmland in Natal and Transvaal. Report to the Department of Mineral and Energy Affairs, South Africa.

Gordon, S. B., Bruce, N. G., Grigg, J., Hibberd, P. L., Kurmi, P., Lam, K. H., Mortimer, K., Asante, K. P., Balakrishnan, K., Balmes, J., Bar-Zeev, N., Bates, M N., Breysse, P. N., Buist, S., Chen, Z., Havens, D., Jack, D., Jindal, S., Kan, H., Mehta, S., Moschovis, P., Naeher, L., Patel, A., Perez-Padilla, R., Pope, D., Rylance, J., Semple, S., Martin II, W. J. 2014.

Respiratory risks from household air pollution in low 
and middle income countries. The Lancet Respiratory Medicine Commission 2(10): 823-860.

Heltberg, R. 2003. Household fuel and energy use in developing countries: A multicounty study. World Bank, Washington DC, USA.

Hiemstra-von der Horst, G. and Hovorka, A. 2008. Reassessing the 'energy ladder': Household energy use in Maun, Botswana. Energy Policy 369: 33333344.

Honkalaskar, V.H., Bhandarkar, U.V., Sohoni, M. 2013. Development of a fuel efficient cookstove through a participatory bottom-up approach. Energy, Sustainability and Society 3(16): 1-21.

Hussain, S., Sanders, B., and Steinert, M. 2012. Participatory design with marginalized people in developing countries: challenges and opportunities experienced in a field study in Cambodia. International Journal of Design 62: 91-109.

Jagdish, K.S. 2004. The development and dissemination of efficient domestic cook stoves and other devices in Karnataka. Current Science 877: 926-931.

Koh, L.P. and Wilcove, D.S. 2008. Is oil palm agriculture really destroying tropical biodiversity? Conservation Letters 12: 60-64.

Manzini, E. and Rizzo, F. 2011. Small projects / large changes: Participatory design as an open participated process. Co-Design: International Journal of CoCreation in Design and the Arts 73(4): 199-215.

Masekoameng, K. E., Similenga, T. E. and Saidi, T. 2005. Household energy needs and utilization patterns in the Giyani rural communities of Limpopo Province, South Africa. Journal of Energy in Southern Africa 16(3): 4-9.

Masera, O. R., Diaz, R. and Berrueta, V. 2005. From cookstoves to cooking systems: The integrated program on sustainable household energy use in Mexico. Energy for Sustainable Development 9(1): 25-36.

Montoya, D., Rogers, L. and Memmott, L. 2012. Emerging perspectives in the restoration of biodiversity-based ecosystem services. Trends in Ecology and Evolution 2712: 666-672.

Muller, C. and Yan, H. 2016. Household fuel use in developing countries: Review of theory and evidence. Online at https://halshs.archivesouvertes.fr/halshs-01290714/document. Viewed May 2016.

Pope, C. A., Burnett, R. T., Thun, M. J., Calle, E. E., Krewski, D., Ito, K. and Thurston, G. D. 2002. Lung cancer, cardiopulmonary mortality and long-term exposure to fine particulate air pollution. Journal of the American Medical Association 287: 1132-1141.

Ramirez, S., Dwivedi, P., Bailis, R., Ghilardi, A. 2012. Perceptions of stakeholders about non-traditional cookstoves in Honduras. Environmental Research Letters 74: 2-11.

Sanchez, T. 2008. Lessons from project implementation on cook stoves and rural electrification, the practical action experience. Technical report, Practical Action, Warwickshire, UK.

Sanders, E.B.N. and Stappers, P.J. 2008. Co-creation and the new landscapes of design. Co-Design: International Journal of Co-Creation in Design and the Arts 41: 5-18.

Smith, K.R., Shuhua, G., Kun, H., and Daxiong, Q. 1993. One hundred million improved cookstoves in China: How was it done? World Development 216: 941-961.

Statistics South Africa 2011. Census 2011: General Household Survey, 2011. Online at http://www.statssa.gov. Viewed April 2014.

Van Veggel, R. 2005. Where the two sides of ethnography collide. Design Issues 213: 3-16.

Wang, Z.A. and Cai, W.J. 2004. Carbon dioxide degassing and inorganic carbon export from a marsh-dominated estuary the Duplin River: A marsh $\mathrm{CO}_{2}$ pump. Limnology Oceanography 492: $341-$ 354.

World Health Organisation. 2014. Burden of disease from household air pollution for 2012. The World Health Organisation. Geneva: Switzerland. Online at http://go.nature.com/smuctx. Viewed September 2015.

Yonemitsu, A., Njenga, M., liyama, M. and Matsushita, S. 2004. Household fuel consumption based on multiple fuel use strategies: A case study in Kibera slums. APCBEE Procedia 10: 331-340. 